Психология. Журнал Высшей школы экономики,

2018. T. 15. № 3. C. 510-526. DOI: 10.17323/1813-8918-2018-3-510-526

\title{
АПРОБАЦИЯ РУССКОЯЗЫЧНОЙ ВЕРСИИ РАСШИРЕННОЙ ШКАЛЫ КУЛЬТУРНОГО ИНТЕЛЛЕКТА
}

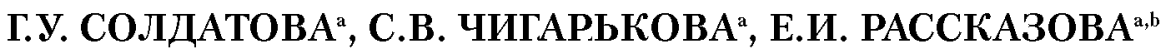

\author{
${ }^{a}$ Московский государственный университет имени М.В. Ломоносова, 119991, Россия, Москва, \\ Летинские горы, Ә. 1 \\ ${ }^{b}$ Национальный исследовательский университет «Высиая икола экономики», 101000, Россия, \\ Москва, ул. Мясниикая, д. 20
}

\begin{abstract}
Резіоме
В статье представлены результаты апробации русскоязычной версии расширенной Шкалы культурного интеллекта (Г.У. Солдатова, С.В. Чигарькова, Е.И. Рассказова). В ситуации интенсификации межкультурного взаимодействия, которая определяет глобальное развитие современного общества, особую значимость приобретает понимание личностных особенностей, обеспечивающих успешность в межкультурной коммуникации. Культурный интеллект понимается как способность индивида эффективно действовать и осуществлять коммуникацию в ситуациях, характеризующихся культурным многообразием. Согласно концепции Кристофера Эрли и Сун Анга, культурный интеллект состоит из четырех компонентов: метакогнитивного, когнитивного, мотивационного и поведенческого. В рамках дальнейшей разработки концепции была предложена дифференцированная структура каждого компонента культурного интеллекта и подготовлена соответствующая методика, что дало возможность более детально изучить данный феномен. На выборке 1545 человек из шести федеральных округов РФ была апробирована русскоязычная версия расширенной Шкалы культурного интеллекта, которую по результатам апробации можно считать надежным и валидным психодиагностическим инструментом. По данным исследования репрезентативной выборки респондентов были доказаны надежность-согласованность и ретестовая надежность методики. Конфирматорный факторный анализ обосновал правомерность выделенной факторной структуры, которая в целом соответствует оригинальному англоязычному варианту, хотя и несколько менее дифференцирована для отдельных компонентов культурного интеллекта. Проверка конвергентной и дискриминантной валидности подтвердила известные данные о корреляции основных шкал методики с личностными чертами Большой пятерки. Также были получены новые данные о связи культурного интеллекта с межкультурной сензитивностью, толерантностью и жизнестойкостью. Методика может применяться в исследованиях межкультурной коммуникации в русскоязычной среде.
\end{abstract}

Ключевые слова: культурный интеллект, межкультурная коммуникация, межкультурная компетентность, психодиагностика, расширенная шкала культурного интеллекта. 
Понятие интеллекта уже давно вышло за пределы школьных стен и сферы образования и широко рассматривается как способность личности адаптироваться к изменяющейся действительности, в том числе к новым ситуациям и участвующим в них людям. Во всех многофакторных теориях интеллекта, начиная с известных концепций Роберта Стернберга и Ховарда Гарднера, а также в других теориях, в которых интеллект обычно предстает как некая совокупность общей способности и ряда специальных, признается множественная природа этого феномена и зависимость его «видов», «модулей» и «составляющих» от социального и культурного контекста. Успешная адаптация и эффективность личности в разных сферах требуют сочетания различных способностей и, следовательно, «интеллектов».

В связи с этим, помимо академического интеллекта, специалисты достаточно рано стали изучать социальный интеллект, определяющий эффективность взаимодействия в обществе. Уже Торндайк и Оллпорт описывают социальный интеллект как особую способность понимать людей, регулировать межличностные отношения и адаптироваться в обществе (Allport, 1937; Thorndike, Stein, 1937). Во всех последующих широко известных концепциях интеллекта социальный интеллект, присутствующий в них под тем или иным названием, также рассматривается как способность к обобщенной и опосредованной познавательной деятельности в социальной среде и как фактор успешности в контексте социального взаимодействия (Eysenck, 1986; Gardner, 1993; Guilford, 1967; Sternberg, 1988). Несмотря на признание высокой значимости данного концепта, он все же долгое время был на периферии внимания ученых (Ушаков, 2004). Но в последние десятилетия интерес к социальному интеллекту и его видам постоянно растет - широко исследуется эмоциональный (Mayer, Salovey, 1993), практический (Стернберг и др., 2002) и даже личностный интеллект (Mayer, 2014; Mayer et al., 2012).

Набирающая скорость культурная глобализация с ее противоречивыми, но активно взаимодействующими процессами (с одной стороны, глобального, с другой - локального, традиционного и специфического) отчетливо определила культурное многообразие в качестве одной из важнейших характеристик современного мира. Различия между расами, народами, культурами, религиями и субкультурами не нивелируются, а остаются выпуклыми и зримыми на всех континентах и во всех странах. Межкультурная компетентность превращается в важное условие эффективного взаимодействия в самых разных сферах - от повседневной жизни в поликультурных обществах до обучения за рубежом или работы в мультинациональных корпорациях. Выделенные виды интеллекта не могут в полной мере объяснить причины успешности взаимодействия в поликультурной среде. Не случайно в начале второго тысячелетия в научном дискурсе появляется и быстро становится востребованным в науке и практике еще один вид интеллекта - культурный (Earley, Ang, 2003), который буквально «висел в воздухе» в контексте многочисленных теорий межкультурной коммуникации и межкультурной компетентности (Солдатова, Шайгерова, 2015).

Структура культурного интеллекта. Соответствующая концепция была создана Кристофером Эрли (Лондонская школа бизнеса, Университет 
Миннесоты) и Сун Ангом (Сингапурский технологический университет). Авторы определили культурный интеллект (cultural intelligence - CQ) как способность индивида эффективно функционировать и взаимодействовать в ситуациях, характеризующихся культурным многообразием. Опираясь на работы Р. Дж. Стернберга, они рассматривают CQ как многомерный феномен, который не ограничен исключительно когнитивной сферой (Sternberg, 2012; Sternberg, Detterman, 1986) и включает четыре компонента: метакогнитивный $\mathrm{CQ}$ (стратегии приобретения и понимания знаний о разных культурах), когнитивный $\mathrm{CQ}$ (общие и структурные знания о культуре), мотивационный $\mathrm{CQ}$ (способность и желание индивида направлять внимание и энергию на культурный контекст), поведенческий CQ (способность осуществлять соответствуюшие вербальные и невербальные действия в межкультурной коммуникации) (Earley, Ang, 2003). При наличии связей с другими видами интеллекта в исследованиях обосновывалась концептуальная самостоятельность CQ, фокусирующегося на решении специфических задач, связанных с культурным контекстом (Ang et al., 2007; Lin et al., 2012; Crowne, 2009, 2013; Kim et al., 2008; Moon, 2010; Rockstuhl et al., 2011; Sahin et al., 2013).

Для выявления уровня CQ и его компонентов Сун Анг вместе с коллегами разработали и апробировали состояшую из 20 утверждений Шкалу культурного интеллекта (CQS) (Ang et al., 2007). Это привело к бурному росту исследований $\mathrm{CQ}$ в организационной психологии, психологии индивидуальных различий, когнитивной психологии, начался процесс адаптации методики в разных странах, в том числе и на русскоязычной выборке (Беловол и др., 2012). Однако по мере накопления эмпирических материалов стали возникать новые задачи и осознаваться существующие значимые лакуны.

В ответ на эти требования была предложена более дифференцированная структура компонентов CQ и создана расширенная Шкала культурного интеллекта (E-CQS) (Van Dyne et al., 2012). Разрабатывая субшкалы культурного интеллекта, Л. Ван Дайн с соавт. опирались на исследования интеллекта и межкультурной коммуникации. Так, на основании исследований по метапознанию (O'Neil, Abedi, 1996; Pintrich, DeGroot, 1990) в структуре метакогнитивного компонента $\mathrm{CQ}$ были выделены: Планирование (подготовка стратегий взаимодействия, формулирование долгосрочных и краткосрочных целей, соотнесение собственных ожиданий и возможных исходов коммуникации в ситуации межкультурного разнообразия); Осознание (процесс осмысления во взаимодействии с представителями другой культуры особенностей психики и поведения представителей своей и других культур, а также специфичности самой межкультурной ситуации общения); Контроль (сравнение и анализ ожиданий и реального межкультурного взаимодействия, соответствующая корректировка представлений и интерпретаций на основании полученного опыта).

Поскольку в культурах сочетаются универсальные и уникальные элементы, когнитивный компонент CQ включил в себя обшие и контекстные знания (Cushner, Brislin, 1996; Murdock, 1987; Triandis, 1994). Обцие знания связаны с универсальными элементами культурных систем (например, экономика, 
право, политика, религия, ценности, язык). Их понимание дает возможность организовывать свои представления о других культурах в целостные модели, проводить обоснованные межкультурные сравнения. Контекстные знания предполагают наличие представлений о специфике проявления универсального в различных сферах жизнедеятельности. Например, при рассмотрении организационной сферы это данные об особенностях ведения переговоров, совершения сделок, организации управления сотрудниками и процессами и т.д. Специфичность культурной сферы может также определяться возрастом, полом, образованием, социальным статусом, профессией и т.д.

На базе современных теорий мотивации были определены основные составляющие мотивационного компонента CQ: внутренняя мотивация (интерес к межкультурному разнообразию, основанный на получении удовольствия от знакомства, общения и взаимодействия с представителями других культур) и внешняя мотивация (заинтересованность в возможных материальных и личных преимуществах, связанных с получением межкультурного опыта) (Deci, Ryan, 1985; Ryan, Deci, 2000), а также самоэффективность в адаптации (как уверенность в способности выполнить конкретную задачу, совладать со стрессами и приспособиться к жизни и работе в различных культурных контекстах) (Bandura, 1997, 2002; Eccles, Wigfield, 2002).

Наконец, на основании теорий межкультурной коммуникации (Hall, 1959, 1976; Gudykunst et al., 1988; Trompenaars, Hampden-Turner, 1998; SpencerOatey, 2008) ключевыми измерениями поведенческого компонента $C Q$ стали гибкость в вербальном поведении (вокализация речи, способность варьировать темп, громкость, эмоциональность, тональность, паузы в соответствии с принятыми в культуре нормами) и невербальном поведении (способность гибко использовать жесты, мимику, позы и язык тела, межличностную дистанцию, зрительный контакт и свой внешний вид для успешной коммуникации с представителями других культур), а также в речевых актах (способность к передаче определенных устойчивых универсальных сообщений в соответствии с культурными стандартами, например, просьбы, приглашения, извинения, благодарность, несогласие и т.д.).

Связь культурного интеллекта с другими психологиескими конструктами. Как показывают исследования, культурный интеллект связан с целым рядом личностных особенностей и диспозиций. Наибольшее внимание исследователей уделялось чертам Большой пятерки. Первое же исследование такого рода (Ang et al., 2006) показало, что CQ как отличается от Большой пятерки, так и имеет содержательные связи с ней. Исследователи предположили, что такая черта, как открытость опыту - тенденция к креативности, воображению и предприимчивости, должна быть наиболее сильно связана с CQ, поскольку включает элементы новизны ситуации. В подтверждение данной гипотезы было выявлено, что открытость опыту положительно связана со всеми компонентами $\mathrm{CQ}$ и является наиболее выраженным его предиктором. Эти данные подтверждались и в дальнейших исследованиях (Ang et al., 2006; Oolders et al., 2008; Sahin et al., 2013; Presbitero, 2016). Опираясь на полученные данные в предыдуших исследованиях, в рамках апробации мы также исследовали отношения 
культурного интеллекта с Большой пятеркой личностных черт. Мы предположили, что наиболее сильные положительные связи среди личностных черт существуют между $\mathrm{CQ}$ и открытостью опыту и экстраверсией, поскольку ситуации межкультурного взаимодействия характеризуются новизной и необходимостью вступать и поддерживать активную коммуникацию.

Можно выделить и другие психологические характеристики, которые могут быть связаны с CQ: жизнестойкость, толерантность, межкультурную сензитивность. Жизнестойкость представляет систему убеждений, определяющую возможность личности преодолевать стресс через снижение внутреннего напряжения. Можно предположить, что в межкультурном общении жизнестойкие убеждения положительно связаны с мотивационным компонентом CQ, поскольку в этом случае особенно важна готовность встретиться со сложными неоднозначными ситуациями и адаптироваться к ним. Толерантность - это психологическая устойчивость личности к проявлениям различного рода инаковости, в том числе и к культурному многообразию мира. Предполагается, что она будет положительно связана со всеми компонентами $\mathrm{CQ}$, поскольку установка на обшение и отношение к другим определяют успешность межкультурного взаимодействия. Для понимания соотношения концепций межкультурной компетентности в исследовании было решено рассмотреть феномен межкультурной сензитивности. Мы предположили, что межкультурная сензитивность будет положительно связана с CQ, поскольку способность различать, понимать и учитывать разнообразные межкультурные контексты важна в ситуации межкультурной коммуникации.

Выбор данных характеристик связан с особенностями ситуаций, определяющимися межкультурным многообразием: неопределенностью, дополнительным напряжением за счет включения культурного измерения в ситуацию общения, необходимостью учета отличных социально-культурных практик и норм и столкновением с другой этнической идентичностью.

Адаптация и апробация русскоязычной версии методики позволят получить психодиагностический инструментарий, с помощью которого будет возможно не только определить выраженность четырех основных компонентов культурного интеллекта, но и детально в них разобраться и глубже исследовать причины и возможности эффективности межкультурного взаимодействия.

\section{Выборка}

В исследовании приняли участие 1545 человек, 1047 (67.8\%) женщин и 498 $(32.2 \%)$ мужчин, в возрасте от 17 лет до 91 года $(\mathrm{M}=28.46, \mathrm{SD}=11.82$ года $)$ из 10 городов шести федеральных округов Российской Федерации. На основании полученного образования 1270 респондентов (82.2\%) указали следующие свои специальности: 441 человек (28.5\%) - психология, 311 (20.1\%) педагогика, 142 (9.2\%) - другие специальности гуманитарного профиля, 68 (4.4\%) - специальности естественно-научного профиля, 114 (7.4\%) - инженерные специальности, 117 (7.6\%) - экономика, 51 (3.3\%) - менеджмент и управление, 26 (1.7\%) - дизайн, искусство, художественное творчество. 


\section{Методики и процедура исследования}

Расширенная Шкала культурного интеллекта. После получения разрешения от авторов методики на ее использование в академических целях был проведен прямой и обратный перевод методики с учетом экспертной оценки. Методика состоит из 4 шкал и 37 утверждений с семибалльной шкалой оценки (от 1 - «полностью не согласен» до 7 - «полностью согласен»), все пункты шкалы - прямые.

Шкала метакогнитивного компонента CQ включает 9 утверждений, по 3 утверждения в каждой субшкале: Планирование («Если у меня планируется важная встреча с представителем другой культуры, я пьтаюсь представить, какие могут быть культурные различия между нами»), Осознание («Я осознаю, как культурное происхождение людей может влиять на их мысли, иувства и действия»), Контроль («B ситуации культурного непонимания $я$ корректирую мои знания о данной культуре»).

Шкала когнит ивного компонента CQ состоит из 10 утверждений, по 5 утверждений в каждой субшкале: Общие знания ( $Я$ имею представления о разных религия х мира») и Контекстные знания ( «Я имею представления о различиях в поведении мужчин и женщин в разньх культурах»).

Шкала мотивационного компонента CQ содержит 9 утверждений, по 3 утверждения в каждой субшкале: Внутренняя мотивация («Меня обогащает взаимодействие с новой для меня культурой»), Внешняя мотивация («Наличие у меня межкультурных контактов и связей могло бы улучиить мою репутацию»), Самооценка возможности адаптации к другой культуре ( $Я$ уверен( $a$ ), ито смогу приспособиться к условиям жизни в другой культуре»).

Шкала поведенческого компонента CQ включает 9 утверждений, по 3 утверждения в каждой субшкале: Вербальное поведение ( $B$ соответствии с культурным окружением я меняю степень эмоциональности своей речи»), Невербальное поведение ( «Я меняю дистаниию, на которой обцаюсь, в зависимости от культуры собеседника»), Речевые акты ( $Я$ меняю способы выражения несогласия в речи в соответствии с культурным окружением»).

Методики для проверки внешней валидности. С целью проверки внешней валидности расширенной Шкалы культурного интеллекта был использован ряд методик. Все респонденты исходной выборки, помимо специально созданной для исследования анкеты, заполнили следующие методики:

1) Большая пятерка личностных черт Р. Маккрае и П. Косты состоит из 75 пунктов с пятибалльной шкалой (от $-2-$ высказывание слева от шкалы выражено сильно до 2 - высказывание справа от шкалы выражено сильно) (Хромов, 2000). Данная модель предлагает пять личностных диспозиций, соответствующих шкалам методики: Экстраверсия $(\alpha=0.78)$, Доброжелательность $(\alpha=0.83)$, Добросовестность $(\alpha=0.83)$, Нейротизм $(\alpha=0.88)$, Открытость опыту $(\alpha=0.78)$.

2) Краткая версия теста жизнестойкости (Осин, Рассказова, 2013) состоит из 24 утверждений, 7 прямых и 17 обратных пунктов (Блок 4). Методика позволяет измерить общий уровень жизнестойкости $(\alpha=0.89)$. 
3) Экспресс-опросник Индекс толерантности Г.У. Солдатовой, О.А. Кравцовой и др. состоит из 22 утверждений с шестибалльной шкалой ответов (от 1 - «абсолютно не согласен» до 6 - «полностью согласен»), 8 прямых и 14 обратных пунктов (Солдатова, Шайгерова, 2008). В соответствии с задачами данного исследования в работу были включены общий показатель и шкала «Этнической толерантности» ( $\alpha$ Кронбаха 0.70 и 0.65 соответственно).

4) Шкала межкультурной сензитивности О.Е. Хухлаева, М.Ю. Чибисовой, вариант Ю.А. Логашенко содержит 50 утверждений со шкалой оценки от 0 («Полностью согласен») до 10 («Полностью не согласен»), 46 прямых и 4 обратных пункта (Логашенко, 2015). Методика включает 4 основные шкалы: Принятие различий, Преуменьшение различий, Абсолютизация различий, Амбивалентность к различиям. В данной работе $\alpha$ Кронбаха по шкалам Принятия и Абсолютизации составляли 0.78 и 0.69 соответственно. Надежность-согласованность двух других шкал была ниже 0.60 , в связи с чем эти шкалы не обсуждаются далее.

Для проверки тест-ретестовой надежности методики 44 студента из исходной выборки заполняли методику диагностики культурного интеллекта дважды с интервалом в три месяца, во время которых они слушали лекционные курсы «Этнопсихология» или «Психология межкультурных коммуникаций».

Сбор данных проводился в 2016-2017 гг. в разных регионах РФ. В сборе данных принимали участие сотрудники и студенты факультета психологии МГУ. имени М.В. Јомоносова, сотрудники Московского государственного психолого-педагогического университета, Волгоградского государственного социально-педагогического университета, Ресурсного центра Тихоокеанского государственного университета, Дагестанского государственного педагогического университета, Казанского государственного университета. 1387 респондентам предъявлялась расширенная Шкала культурного интеллекта в бумажном варианте, 158 респондентам - в электронном. Данные собирались анонимно.

Обработка данных проводилась в программах IBM SPSS Statistics 23.0 и Mplus 7.

\section{Описание результатов}

\section{Надежность-согласованность шкаль}

Основные шкалы методики характеризуются высокой надежностью-согласованностью ( $\alpha$ Кронбаха во всех случаях превышает 0.80 , таблица 1 ). Надежность-согласованность субшкал методики ниже (0.62-0.79).

\section{Факторная структура Шкаль культурного интеллекта}

При помощи конфирматорного факторного анализа исследовались показатели модели, включающей 11 первичных субшкал и 4 вторичных коррелируюших фактора, ее превосходство над альтернативными моделями было 
Описательная статистика, надежность-согласованность субшкал Шкалы культурного интеллекта

\begin{tabular}{|c|c|c|c|c|c|}
\hline \multicolumn{2}{|c|}{$\begin{array}{c}\text { Субшкалы Шкалы культурного } \\
\text { интеллекта }\end{array}$} & Среднее & Ст. откл. & $\begin{array}{c}\alpha \text { Кронбаха } \\
(N=1545)\end{array}$ & $\begin{array}{l}\text { Тест-рестовая } \\
\text { корреляция } r\end{array}$ \\
\hline \multicolumn{2}{|c|}{$\begin{array}{l}\text { Культурный интеллект - общий } \\
\text { балл }\end{array}$} & 169.17 & 29.78 & 0.93 & $0.62^{* *}$ \\
\hline \multicolumn{2}{|c|}{ Когнитивный компонент $\mathrm{CQ}$} & 44.43 & 9.46 & 0.85 & $0.67 * *$ \\
\hline \multicolumn{2}{|c|}{ Метакогнитивный компонент CQ } & 43.16 & 8.39 & 0.83 & $0.52^{* *}$ \\
\hline \multicolumn{2}{|c|}{ Мотивационный компонент CQ } & 43.26 & 8.62 & 0.82 & $0.69^{* *}$ \\
\hline \multicolumn{2}{|c|}{ Поведенческий компонент CQ } & 38.32 & 9.46 & 0.86 & $0.67 * *$ \\
\hline \multirow{2}{*}{$\begin{array}{l}\text { Субшкалы } \\
\text { когнитивного } \\
\text { компонента } \\
\mathrm{CQ}\end{array}$} & $\begin{array}{l}\text { Контекстные } \\
\text { знания }\end{array}$ & 21.51 & 5.37 & 0.82 & $0.70^{* *}$ \\
\hline & Общие знания & 22.93 & 4.96 & 0.68 & $0.60^{* *}$ \\
\hline \multirow{3}{*}{$\begin{array}{l}\text { Субшкалы } \\
\text { метакогнитив- } \\
\text { ного компо-- } \\
\text { нента CQ }\end{array}$} & Осознание & 15.56 & 3.24 & 0.68 & $0.30 *$ \\
\hline & Планирование & 13.08 & 3.65 & 0.71 & $0.59^{* *}$ \\
\hline & Контроль & 14.52 & 3.21 & 0.79 & $0.46^{* *}$ \\
\hline \multirow{3}{*}{$\begin{array}{l}\text { Субшкалы } \\
\text { мотивацион- } \\
\text { ного компо- } \\
\text { нента CQ }\end{array}$} & $\begin{array}{l}\text { Внешняя } \\
\text { мотивация }\end{array}$ & 14.13 & 3.64 & 0.62 & $0.65^{* *}$ \\
\hline & $\begin{array}{l}\text { Внутренняя } \\
\text { мотивация }\end{array}$ & 14.89 & 3.65 & 0.72 & $0.60^{* *}$ \\
\hline & $\begin{array}{l}\text { Самоэффективность } \\
\text { в адаптации }\end{array}$ & 14.25 & 3.31 & 0.73 & $0.72 * *$ \\
\hline \multirow{3}{*}{$\begin{array}{l}\text { Субшкалы } \\
\text { поведенчес- } \\
\text { кого компо- } \\
\text { нента CQ }\end{array}$} & Речевые акты & 12.98 & 3.61 & 0.67 & $0.62^{* *}$ \\
\hline & $\begin{array}{l}\text { Вербальное } \\
\text { поведение }\end{array}$ & 12.38 & 3.57 & 0.65 & $0.55^{* *}$ \\
\hline & $\begin{array}{l}\text { Невербальное } \\
\text { поведение }\end{array}$ & 12.95 & 3.63 & 0.69 & $0.61 * *$ \\
\hline
\end{tabular}

${ }^{*} p<0.05,{ }^{* *} p<0.01$.

продемонстрировано авторами оригинальной версии (Van Dyne et al., 2012). Разрешались корреляции ошибок между пунктами, относящимися к одной вторичной шкале, если они были содержательно обоснованы (Little, 2013). Например, из трех пунктов, входящих в субшкалу внутренней мотивации, пункт «Меня обогащает взаимодействие с новой для меня культурой» дополнительно связан с пунктом «Мне нравится взаимодействовать с представи- 
телями других национальностей и культур» формой утверждения - о взаимодействии, тогда как третий пункт сформулирован скорее о репутации и наличии связей: «Наличие у меня межкультурных контактов и связей могло бы улучиить моюо репутацио».

Кроме того, согласно индексам модификации, ответы на пункты методики существенным образом зависят от ответов испытуемых на предыдущий пункт. Для социально-психологических исследований такой ауторегрессивный әффект - не редкость (Ibid.), но поскольку в данной методике этот эффект представляет ошибку измерения, он также задавался в модели ${ }^{1}$. Итоговая модель характеризуется хорошим соответствием эмпирическим данным (CFI $=0.92$, RMSEA $=0.046$ [95\%CI 0.044-0.048], SRMR $=0.047$, $\chi^{2} / \mathrm{df}=4.24-$ см. рисунок 1$)$.

\section{Внешняя валидность ШКкаль культурного интеллекта}

Для проверки внешней валидности субшкал культурного интеллекта рассчитывались корреляции с показателями других методик (таблица 2).

При анализе корреляций с личностными чертами Большой пятерки были выявлены слабые связи «Экстраверсии» и «Открытости опыту» с общим показателем культурного интеллекта, а также с мотивационным и когнитивным компонентами.

Мы также провели сравнение культурного интеллекта с показателями жизнестойкости и толерантности. Жизнестойкость оказалась связана со всеми компонентами культурного интеллекта, более высокие корреляции были обнаружены при сравнении с субшкалой мотивационного компонента Самоэффективность в адаптации. Общая толерантность связана с общим показателем культурного интеллекта и всеми его компонентами, но наиболее выражена связь с мотивационным компонентом. Более высокие показатели такой связи демонстрирует субшкала Этнической толерантности. При детальном анализе наиболее сильная корреляция обнаружена между Этнической толерантностью и Внутренней мотивацией. Наиболее высокие показатели взаимосвязи $\mathrm{CQ}$ и межкультурной сензитивностью были выявлены между шкалой Принятия и общим показателем культурного интеллекта, а также мотивационным, метакогнитивным и поведенческим компонентами.

\section{Тест-ретестовая надежность шкальь}

Корреляционный анализ подтверждает устойчивость во времени (тестретестовую надежность - таблица 1) большинства компонентов культурного интеллекта. Лишь в двух случаях тест-ретестовая корреляция не превышает

Поскольку полный перечень ауторегрессивных связей делает изображение результатов конфирматорного анализа чрезмерно громоздким, на рисунке 1 представлены лишь основные связи. Полный перечень ауторегрессивных эффектов может быть предоставлен авторами по запросу. 
Рисунок 1

Результаты конфирматорного факторного анализа Шкалы культурного интеллекта

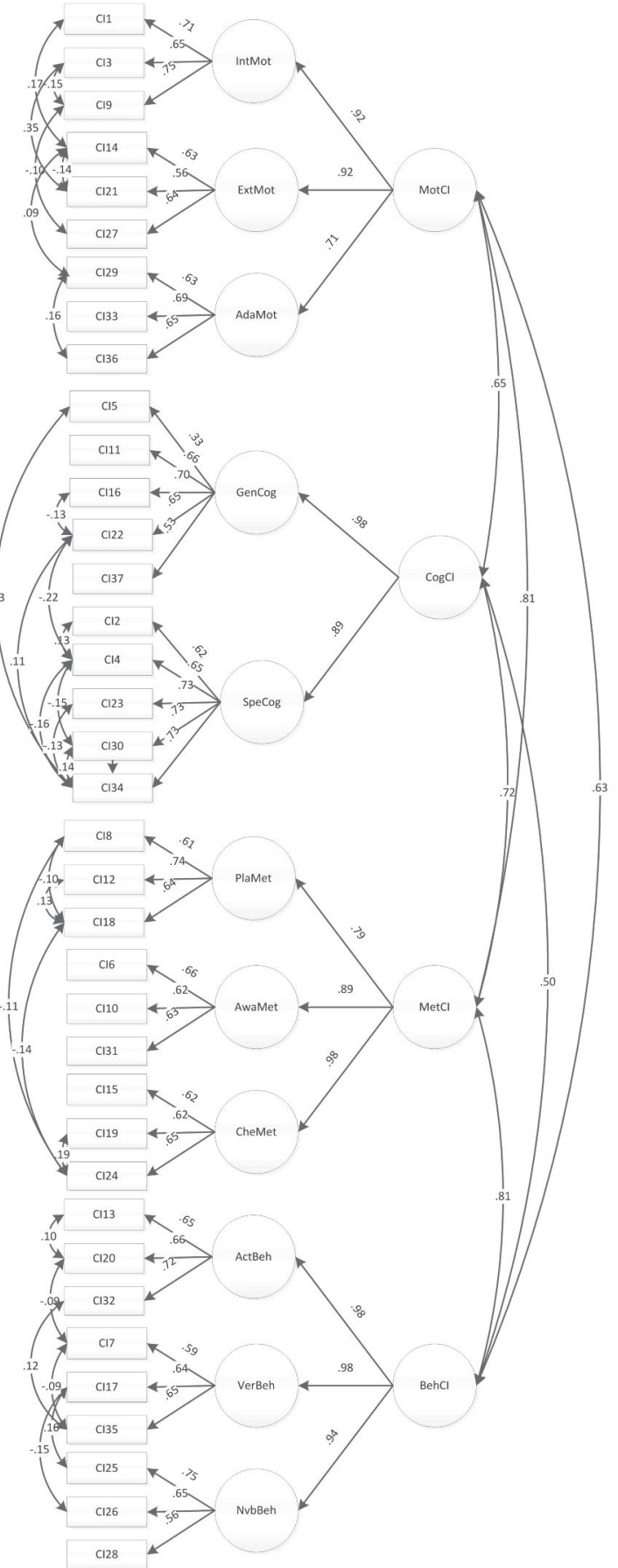


Корреляции ШКклы культурного интеллекта с другими методиками ${ }^{2}$

\begin{tabular}{|c|c|c|c|c|c|}
\hline & \multirow{2}{*}{$\begin{array}{c}\mathrm{CQ}- \\
\text { общий } \\
\text { балл }\end{array}$} & \multicolumn{4}{|c|}{ Компоненты культурного интеллекта } \\
\hline & & $\begin{array}{l}\text { Мотива- } \\
\text { ционный }\end{array}$ & $\begin{array}{c}\text { Когнитив- } \\
\text { ный }\end{array}$ & $\begin{array}{c}\text { Метако- } \\
\text { гнитивный }\end{array}$ & $\begin{array}{c}\text { Поведен- } \\
\text { ческий }\end{array}$ \\
\hline \multicolumn{6}{|l|}{ Больиая пятерка } \\
\hline Экстраверсия & $0.219 * *$ & $0.247^{* *}$ & $0.205^{* *}$ & $0.119 * *$ & $0.146^{* *}$ \\
\hline Доброжелательность & $0.194 * *$ & $0.163^{* *}$ & $0.101^{* *}$ & $0.163^{* *}$ & $0.213^{* *}$ \\
\hline Добросовестность & $0.092 * *$ & $0.077^{*}$ & 0.004 & $0.140^{* *}$ & $0.090 * *$ \\
\hline Нейротизм & -0.046 & $-0.077^{*}$ & -0.041 & -0.052 & 0.014 \\
\hline Открытость опыту & $0.270 * *$ & $0.277^{* *}$ & $0.264^{* *}$ & $0.163^{* *}$ & $0.183^{* *}$ \\
\hline Жизнестойкость & $0.167 * *$ & $0.185^{* *}$ & $0.121 * *$ & $0.170^{* *}$ & $0.082 * *$ \\
\hline \multicolumn{6}{|l|}{ Индекс толерантности } \\
\hline Общая толерантность & $0.259^{* *}$ & $0.331^{* *}$ & $0.179^{* *}$ & $0.152^{* *}$ & $0.194^{* *}$ \\
\hline Этническая толерантность & $0.291 * *$ & $0.390^{* *}$ & $0.228 * *$ & $0.143 * *$ & $0.198 * *$ \\
\hline \multicolumn{6}{|c|}{ Межкультурная сензитивность } \\
\hline Принятие & $0.444^{* *}$ & $0.379^{* *}$ & $0.267^{* *}$ & $0.442 * *$ & $0.387^{* *}$ \\
\hline Абсолютизация & $0.087 * *$ & $0.183^{* *}$ & $0.064^{*}$ & -0.006 & 0.045 \\
\hline
\end{tabular}

${ }^{*} p<0.05,{ }^{* *} p<0.01$.

0.50: относительно нестабильны Осознание и Контроль как компоненты метакогнитивного культурного интеллекта. Результаты сравнения показателей культурного интеллекта при первом и втором замерах указывают, что общий балл культурного интеллекта повышается при ретесте $(t=-2.62, p<0.05)$ за счет повышения показателей по когнитивному $(t=-2.83, p<0.01)$ и поведенческому $(t=-2.28, p<0.05)$ компонентам.

\section{Обсуждение результатов}

В целом результаты свидетельствуют в пользу надежности и валидности Шкалы культурного интеллекта.

Факторнал структура шкаль. Конфирматорный факторный анализ подтверждает факторную структуру методики, включающую 11 первичных шкал

${ }^{2}$ Полная матрица корреляций и психометрические показатели других методик не приводятся ввиду громоздкости и могут быть предоставлены авторами по запросу. 
и 4 коррелирующие вторичные шкалы. Тем не менее важно отметить, что ответы испытуемых на вопросы методики зависят от предыдущего вопроса, и этот ауторегрессивный эффект был учтен в конфирматорной модели для большей части пунктов методики.

Надежность-согласованность икаль. Основные шкалы методики характеризуются высокой надежностью-согласованностью, что соответствует полученным на основе более краткой версии методики данным, где альфа Кронбаха варьирует для разных шкал и выборок 0.71-0.85 (Van Dyne et al., 2008). Надежность-согласованность субшкал методики ниже, однако, учитывая, что в большинство из них входит три пункта, эти показатели также допустимы.

Внеиняя валидность. Полученные данные подтверждают результаты исследований авторов данной методики как о самостоятельности конструкта культурного интеллекта, так и о наличии определенных связей с личностными чертами (Van Dyne et al., 2017). Положительная связь культурного интеллекта с такими личностными чертами, как открытость опыту и экстраверсия, показывает, что успешность межкультурного взаимодействия, особенно в контексте желания вступать в контакт с другими культурами и наличия широкого кругозора, определяется личностными особенностями в получении удовольствия, в первую очередь, от новизны ситуации и разнообразия общения.

Все компоненты культурного интеллекта положительно связаны с толерантностью, особенно с этнической толерантностью, и компонентом межкультурной сензитивности - принятием культурных различий, а жизнестойкость положительно связана с субшкалой Самоэффективность в адаптации. Наиболее сильные положительные связи среди личностных черт Большой пятерки существуют между $\mathrm{CQ}$, Открытостью опыту и Экстраверсией. Таким образом, наши гипотезы подтвердились: анализ корреляций компонентов и субкомпонентов Шкалы культурного интеллекта продемонстрировал наличие связей с рядом показателей, значимых в межкультурном взаимодействии.

Тест-ретестовая надежность икаль. Несмотря на малый размер подвыборки, результаты тест-ретестовой надежности согласуются как с полученными для оригинальной версии данными о стабильности основных компонентов культурного интеллекта (Van Dyne et al., 2008), так и с данными о возможности изменения культурного интеллекта под действием различных внешних и внутренних факторов (Earley, Ang, 2003). Полученные данные о росте общего показателя CQ при втором замере полностью совпадают с данными апробации краткой оригинальной версии (Van Dyne et al., 2008), которые авторы объясняют тем, что между двумя замерами респонденты изучали культурные ценности и участвовали в ролевых играх. В данном исследовании студенты также слушали курсы и участвовали в семинарах, связанных с культурным контекстом, - «Этнопсихология» и «Психология межкультурных коммуникаций», что свидетельствует о возможности развития культурного интеллекта в процессе обучения.

Таким образом, русскоязычная версия расширенной Шкалы культурного интеллекта является надежным и валидным психодиагностическим инструментом. По 
данным исследования репрезентативной выборки респондентов были доказаны надежность-согласованность и ретестовая надежность методики. Конфирматорный факторный анализ обосновал правомерность выделенной факторной структуры, которая соответствует оригинальному англоязычному варианту. Проверка конвергентной и дискриминантной валидности подтвердила известные данные о корреляции основных шкал методики с личностными чертами Большой пятерки. Были выявлены связи Экстраверсии и Открытости опыту с общим показателем культурного интеллекта, а также с мотивационным и когнитивным компонентами, получены новые данные о связи культурного интеллекта с межкультурной сензитивностью, толерантностью и жизнестойкостью. Все компоненты культурного интеллекта положительно связаны с толерантностью, особенно с Этнической толерантностью, и шкалой Принятия культурных различий, а жизнестойкость положительно связана с субшкалой Самоэффективность в адаптации.

\section{Литература}

Беловол, Е. В., Шкварило, К. А., Хворова, Е. М. (2012). Адаптация опросника «Шкала культурного интеллекта» К. Эрли и С. Анга на русскоязычной выборке. Вестник Российского университета дружбы народов. Серия Психология и педагогика, 4, 5-14.

Логашенко, Ю. А. (2015). Межкультурная сенситивность студентов в полиэтниной среде (Кандидатская диссертация). Санкт-Петербургский государственный университет, СанктПетербург.

Осин, Е. Н., Рассказова, Е. И. (2013). Краткая версия теста жизнестойкости: психометрические характеристики и применение в организационном контексте. Вестник Московского университета. Серия 14. Психология, 2, 147-165.

Солдатова, Г. У., Шайтерова, Л. А. (ред.). (2008). Психодиагностика толерантности лииности. М.: Смысл.

Солдатова, Г. У., Шайгерова, Л. А. (2015). Рефлексия множественности выбора в психологии межкультурных коммуникаций. Психологиеские исследования, 8(40), 10. Режим доступа: http://psystudy.ru/index.php/num/2015v8n40/1118-soldatova40.html

Стернберг, Р. Дж., и др. (ред.). (2002). Практицеский интеллект. СПб.: Питер.

Ушаков, Д. В. (2004). Социальный интеллект как вид интеллекта. В кн. Д. В. Люсин, Д. В. Ушаков (ред.), Социальный интеллект: теория, измерение, исследования (с. 11-29). М.: Институт психологии РАН.

Хромов, А. Б. (2000). Пятифакторный опросник лииности: уиебно-методическое пособие. Курган: Изд-во Курганского государственного университета.

Ссылки на зарубежные источники см. в разделе References после анллоязиного блока. 
Солдатова Галина Уртанбековна - профессор, кафедра психологии личности, факультет психологии, МГУ имени М.В. Ломоносова, член-корреспондент РАО, доктор психологических наук.

Сфера научных интересов: психология межэтнических отношений, психология межкультурных коммуникаций, исследование социально-психологических аспектов влияния Интернета на развитие личности и общества.

Контакты: soldatova.galina@gmail.com

Чигарькова Светлана Вячеславна - инженер, кафедра психологии личности, факультет психологии, МГУ имени М.В. Ломоносова.

Сфера научных интересов: психология межкультурных коммуникаций, межкультурная компетентность личности, психология личности, этническая идентичность, цифровая социализация, цифровое детство.

Контакты: chigars@gmail.com

Рассказова Елена Игоревна - доцент, кафедра нейро- и патопсихологии, факультет психологии, МГУ имени М.В. Ломоносова; ведущий научный сотрудник, международная лаборатория позитивной психологии личности и мотивации, Национальный исследовательский университет «Высшая школа экономики», кандидат психологических наук.

Сфера научных интересов: психология саморегуляции, позитивная психология, психосоматика, психология здоровья, математические методы в психологии.

Контакты: e.i.rasskazova@gmail.com

\title{
Approbation of Expanded Cultural Intelligence Scale in Russian
}

\author{
G.U. Soldatova ${ }^{a}$, S.V. Chigarkova ${ }^{a}$, E.I. Rasskazova ${ }^{a, b}$
}

${ }^{a}$ Lomonosov Moscow State University, 1 Leninskie Gory, Moscow, 119991, Russian Federation

${ }^{b}$ National Research University Higher. School of Economics, 20 Myasnitskaya Str., Moscow, 101000, Russian Federation

\begin{abstract}
The paper presents the results of approbation of the Expanded Cultural Intelligence Scale in Russia. Due to the growing intercultural interaction in a modern global society, it becomes important to study personal characteristics that ensure success during intercultural communication. Cultural intelligence is the capability of an individual to act and communicate effectively in culturally diverse settings. According to the concept of C. Earley and S. Ang, cultural intelligence consists of four factors: metacognitive, cognitive, motivational and behavioral. Differentiated structure of each factor of cultural intelligence, proposed later, enabled a more detailed study of this phenomenon. 1545 respondents completed the Russian version of the ECQS. According to the results of our approbation, the E-CQS can be considered a reliable and valid psychodiagnostic tool in Russia. Research on a representative Russian sample revealed good consistency and test-retest reliability of the E-CQS. Confirmatory factor analysis supported a factor structure, which is generally consistent with the original English version. Results on convergent and discriminant validity are in line with published data about the correlation of the main scales of the E-CQS with personal traits measured by the Big Five. Also, new data were obtained on the relationship between cultural intelligence and intercultural sensitivity, tolerance
\end{abstract}


and hardiness. The E-CQS can be used in studies of intercultural communication among Russian speakers.

Keywords: cultural intelligence, intercultural communication, intercultural competence, psychodiagnostics, expanded scale of cultural intelligence.

\section{References}

Allport, G. W. (1937). Personality: A psychological interpretation. New York: Henry Holt.

Ang, S., Van Dyne, L., \& Koh, C. (2006). Personality correlates of the four-factor model of cultural intelligence. Group and Organization Management, 31, 100-123. doi:10.1177/1059601105275267

Ang, S., Van Dyne, L., Koh, C., Ng, K.-Y., Templer, K. J., Tay, C., \& Chandrasekar, N. A. (2007) Cultural intelligence: Its measurement and effects on cultural judgment and decision making, cultural adaptation and task performance. Management and Organization Review, 3, 335-371. doi:10.1111/j.1740-8784.2007.00082.x

Bandura, A. (1997). Self-efficacy: The exercise of control. New York: W.H. Freeman.

Bandura, A. (2002). Social cognitive theory in a cultural context. Applied Psychology: An International Review, 51, 269-290.

Belovol, E. V., Shkvarilo, K. A., \& Khvorova, E. M. (2012). Russian-language verification of P. C. Earley and S. Ang's "Cultural Intelligence Scale". RUDN Journal of Psychology and Pedagogics, 4 , 5-14. (in Russian)

Crowne, K. A. (2009). The relationships among social intelligence, emotional intelligence and cultural intelligence. Organization Management Joumal, 6, 148-163.

Crowne, K. A. (2013). An empirical analysis of three intelligences. Canadian Journal of Behavioural Science, 45, 105-114.

Cushner, K., \& Brislin, R. W. (1996). Intercultural relations: A practical guide (2nd ed.). Thousand Oaks, CA: Sage.

Deci, E. L., \& Ryan, R. M. (1985). Intrinsic motivation and self-determination in human behavior. New York: Plenum.

Earley, P. S., \& Ang, S. (2003). Cultural intelligence: individual interactions across cultures. Palo Alto, CA: Stanford University Press.

Eccles, J. S., \& Wigfield, A. (2002). Motivational beliefs, values, and goals. Annual Reriew of Psychology, 53, 109-132.

Eysenck, H. J. (1986). The theory of intelligence and the psychophysiology of cognition. Advances in Psychology of Human Intelligence, 3, 1-34.

Gardner, H. (1993). Multiple intelligences: The theory in practice. New York: Basic Books.

Gudykunst, W. B., Ting-Toomey, S., \& Chua, E. M. (1988). Culture and interpersonal communication. Newbury Park, CA: Sage.

Guilford, J. P. (1967). The nature of human intelligence. New York: McGraw-Hill.

Hall, E. T. (1959). The silent language. New York: Anchor Books.

Hall, E. T. (1976). Beyond Culture. New York: Doubleday.

Khromov, A. B. (2000). Pyatifaktomyi oprosnik lichnosti [Five-factor personality questionnaire] Kurgan: Kurgan State University. (in Russian) 
Kim, K., Kirkman, B. L., \& Chen, G. (2008). Cultural intelligence and international assignment effectiveness. In S. Ang \& L. Van Dyne (Eds.), Handbook of cultural intelligence: Theory, measurement, and applications (pp. 71-90). New York: M.E. Sharpe.

Lin, Y.-Ch., Chen, A. S.-Y., \& Song Y.-C. (2012). Does your intelligence help to survive in a foreign jungle? The effects of cultural intelligence and emotional intelligence on cross cultural adjustment. Intermational Joumal of Intercultural Relations, 36, 541-552.

Little, T. D. (2013). Longitudinal structural equation modeling. New York: Guilford Press.

Logashenko, Yu. A. (2015). Mezhkul'tumaya sensitionost' studentov v polietnichnoi srede [Intercultural sensitivity of students in multiethnic environment] ( $\mathrm{PhD}$ disseration). Saint Petersburg State University, Saint Petersburg, Russian Federation. (in Russian)

Mayer, J. D. (2014). Personal intelligence: The power of personality and how it shapes our lives. New York: Scientific American/Farrar, Straus and Giroux.

Mayer, J., Panter, A., \& Caruso, D. (2012). Does personal intelligence exist? Evidence from a new ability-based measure. Joumal of Personality Assessment, 94, 124-140.

Mayer, J. D., \& Salovey, P. (1993). The intelligence of emotional intelligence. Intelligence, 17, 433-442.

Moon, T. (2010). Emotional intelligence correlates of the four-factor model of cultural intelligence. Journal of Managerial Psychology, 25, 876-898. doi:10.1108/ 02683941011089134

Murdock, G. P. (1987). Outline of cultural materials (5th rev. ed.). New Haven, CT: HRAF.

O'Neil, H. E., \& Abedi, J. (1996). Reliability and validity of a state metacognitive inventory: Potential for alternative assessment. The Joumal of Educational Research, 89, 234-245.

Oolders, T., Chernysherdco, O. S., \& Stark, S. (2008). Cultural intelligence as a mediator of relationships between Openness to Experience and adaptive performance. In S. Ang \& L. Van Dyne (Eds.), Handbook of cultural intelligence: Theory, measurement, and applications (pp. 145-158). New York: M. E. Sharpe.

Osin, E. N., \& Rasskazova, E. I. (2013). A short version of the Hardiness Test: Psychometric properties and organizational application. Vestnik Moskozskogo Universiteta. Seriya 14. Psikhologiya, 2, 147-165. (in Russian)

Pintrich, P. R., \& De Groot, E. V: (1990). Motivational and self-regulated learning components of classroom academic performance. Journal of Educational Psychology, 82, 33-40.

Presbitero, A. (2016). Cultural intelligence (CQ) in virtual, cross-cultural Interactions: generalizability of measure and links to personality dimensions and task performance. International Joumal of Intercultural Relations, 50, 29-38.

Rockstuhl, T., Seiler, S., Ang, S., Van Dyne, L., \& Annen, H. (2011). Beyond general intelligence (IQ) and emotional intelligence (EQ): The role of cultural intelligence (CQ) on cross-border leadership effectiveness in a globalized world. Joumal of Social Issues, 67, 825-840.

Ryan, R. M., \& Deci, E. L. (2000). Intrinsic and extrinsic motivations: Classic definitions and new directions. Contemporary Educational Psychology, 25, 54-67.

Sahin, F., Gurbuzb, S., Köksal, O., \& Ercan, Ü. (2013). Measuring cultural intelligence in the Turkish context. International Joumal of Selection and Assessment, 21(2), 135-144.

Soldatova, G. U., \& Shaigerova, L. A. (2015). Reflection upon multiplicity of choice in psychology of intercultural communication. Psikhologicheskie Issledovaniya, 8(40), 10. Retrieved from http://psystudy.ru (in Russian)

Soldatova, G. U., \& Shaigerova, L. A. (Eds.). (2008). Psikhodiagnostika tolerantnosti lichnosti [Psychodiagnostics of personal tolerance]. Moscow: Smysl. (in Russian)

Spencer-Oatey, H. (2008). Face, (im)politeness, and rapport. In H. Spencer-Oatey (Ed.), Culturally speaking: Culture, communication, and politeness theory (pp. 11-47). London: Continuum. 
Sternberg, R. J. (1988). The triarchic mind: A new theory of human intelligence. New York: Penguin Books.

Sternberg, R. J. (2012). Intelligence in its cultural context. In M. J. Gelfand, C.-Y. Chiu, Y.-Y. Hong

(Eds.), Advances in culture and psychology (Vol. 2, pp. 205-248). New York: Oxford University Press.

Sternberg, R. J., \& Detterman, D. K. (1986). What is Intelligence? Contemporary viewpoints on its nature and definition. Norwood, NJ: Ablex.

Sternberg, R. J., et al. (Eds.). (2002). Prakticheskii intellekt [Practical intelligence]. Saint Petersburg: Piter. (in Russian) (Transl. of: Sternberg, R, J., et al. (Eds.). (2000). Practical intelligence in everyday life. Cambridge, UK: Cambridge University Press.)

Thorndike, R. L., \& Stein, S. (1937). An evaluation of the attempts to measure social intelligence. Psychological Bulletin, 34, 275-285.

Triandis, H. C. (1994). Culture and social behavior. New York: McGraw-Hill.

Trompenaars, F., \& Hampden-Turner, C. (1998). Riding the waves of culture: Understanding diversity in global business. New York: McGraw Hill.

Ushakov, D. V. (2004). Sotsial'nyi intellekt kak vid intellekta [Social intelligence as a type of intelligence]. In D. V. Lyusin \& D. V. Ushakov (Eds.), Sotsial'myi intellekt: teoriya, izmerenie, issledovaniya [Social intelligence: Theory, measurement, research] (pp. 11-29). Moscow: Institute of Psychology of RAS. (in Russian)

Van Dyne L., Ang, S., \& Tan, M.-L. (2017). Cultural intelligence. Oxford bibliographies. Oxford, UK: Oxford University Press.

Van Dyne, L., Ang, S., \& Koh, C. (2008). Development and validation of the CQS. In S. Ang \& L. Van Dyne (Eds.), Handbook of cultural intelligence: Theory, measurement, and applications (pp. 16-38). New York: M.E. Sharpe.

Van Dyne, L., Ang, S., Ng, K.-Y., Rockstuhl, T., Tan, M. L., \& Koh, C. (2012). Sub-dimensions of the four factor model of cultural intelligence: Expanding the conceptualization and measurement of cultural intelligence (CQ). Social and Personal Psychology: Compass, 6(4), 295-313.

Galina U. Soldatova - professor, Department of Psychology of Personality, Faculty of Psychology, Lomonosov Moscow State University, corresponding member of the Russian Academy of Education, D.Sc.

Research area: psychology of interethnic relations, psychology of intercultural communications, psychology of identity, conflict and interethnic tension, the socio-psychological aspects of the influence of the Internet on the development of the individual and society.

E-mail: soldatova.galina@gmail.com

Svetlana V. Chigarkova - assistant, Department of Psychology of Personality, Faculty of Psychology, Lomonosov Moscow State University.

Research area: psychology of intercultural communications, intercultural competence of personality, personality psychology, ethnic identity, digital socialization, digital childhood.

E-mail: chigars@gmail.com

Elena I. Rasskazova - assistant professor, department of Clinical Psychology, Faculty of Psychology, Lomonosov Moscow State University; leading research fellow, International Laboratory of Positive Psychology of Personality and Motivation, National Research University Higher School of Economics, Ph.D.

Research area: psychology of self-regulation, positive psychology, psychosomatics, health psychology, mathematical methods in psychology.

E-mail: e.i.rasskazova@gmail.com 